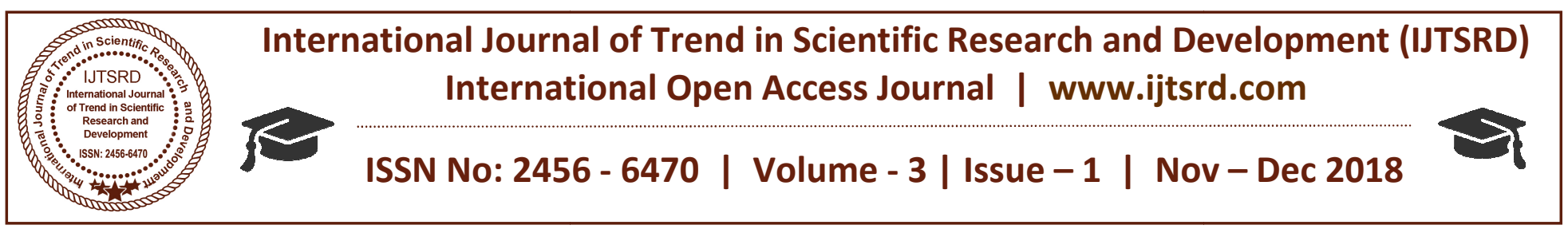

\title{
Euthanasia, Suicide and Physician-Assisted Suicide; An Impression
}

\author{
Yazhini. R, Swaraj L. K \\ B.BA, L.LB. (HONS), Shanmugha Arts, Science, Technology \&Research Academy, \\ Thirumalaisamudram, Thanjavur, Tamil Nadu, India
}

\begin{abstract}
The most painful loss in a person's existence would be the loss of his wholesome health. Each and every being in this world is living a competitive life in order for their survival and to defeat death. But, astonishingly, some people seek their own death and request other fellow beings for their end. These circumstances occur only when the person has gone through hard-hitting mental, physical, and psychological problems. The ways that are used to end their lives are suicide, euthanasia, physicianassisted suicide and similar ways. This paper speaks and explains about how these forms work and the requirements or guidelines for the functioning of the said forms. First, introductorily, the meaning and working of each form are described. Introducing with the euthanasia, its guidelines, related cases that the Court has witnessed, and the legal position of it as of now. Then, the author explains the meaning and working of physician-assisted suicide. The drugs used and further elucidations are given. Finally, familiarizing about suicide, position of suicide in India, and the statistics regarding the rate of suicides reported and the cases related to it. Thus, the paper talks about the major three formulae that is used as a tool to end the pain suffering.
\end{abstract}

KEY WORDS: euthanasia, suicide, physicianassisted suicide, lethal drugs

\section{INTRODUCTION}

Suicide, euthanasia and physician-assisted suicide are the forms which are performed for the basic yield "death". The way it is performed, the person who is performing it and the reason behind the death differ. Suicide is the act of deliberately causing his own death. There may be many personal reasons for committing suicide. Euthanasia is intentionally causing someone's death in order to relive then from pain and suffering. Physician-assisted suicide is committing suicide with the assistance of the physician. Euthanasia and PAS are performed to give relief to the patients who are suffering from terminal illness and has no chance of recovery. All the three forms have different guidelines, requirements, and necessities.

\section{EUTHANASIA:}

As per the definition is given by the Black's Law Dictionary (8th edition) euthanasia means the act or practice of killing or bringing about the death of a person who suffers from an incurable disease or condition, especially a painful one, for a reason of mercy. There has also been a confusion regarding the difference between suicide \& euthanasia. It has been distinguished in the case Naresh MarotraoSakhre $\boldsymbol{v}$. Union of India ${ }^{\boldsymbol{I}}$, J. Lodha clearly said in this case, "Euthanasia or mercy killing means \& implies the intervention of other human agency to end the life. Thus, euthanasia or mercy killing is nothing but homicide whatever the circumstances in which it is affected."

\section{TYPES OF EUTHANASIA:}

\section{$>$ Passive euthanasia}

is usually defined as withdrawal of medical treatment with a deliberate intention of causing the patient's death. If a patient is in a coma or on the heart-lung machine, withdrawal of the machine and not giving lifesaving medicines like antibiotics in certain situations may result in passive euthanasia. In this form of euthanasia, the doctor on the request of the patient or his family stops the necessary element. For example, stopping the medication, removing the feeding pipe, allows the person to dehydrate and so on. These are not for the lay man and only for the patients who are declared terminally ill and there is no

${ }^{1}$ Naresh MarotraoSakhre v. Union of India (1996) 1 BomCR 92. 
chance for the person to recover. When the patient has no chance of recovery the family itself will request for the discharge and the patient dies within days due to the lack of medications.

Some patients will be placed on a ventilator. If there is no chance for the patient to recover, then the doctor on request of the family will turn off the ventilator. And another form is to subjection to morphine. Morphine is a drug which reduces pain and over dose of it may cause death.

\section{Active euthanasia}

is taking specific steps to cause the patient's death, such as injecting the patient with some lethal substance, for example, sodium pentothal which causes a person deep sleep in a few seconds, and the person instantaneously \& painlessly dies in this deep sleep. This is the act of deliberately ending the person's life from suffering and pain. This is debated to be similar to passive euthanasia. The base reason for both the forms is to end a person's life. Thus, euthanasia is called "mercy killing".

This euthanasia and physician-assisted suicide is not legally accepted because it is considered as murder. Even though there is a lot of controversy on the legalization of these forms, it is been approved in some parts of the world.

The basic distinction between active and passive euthanasia is people don't mostly approve the former and the latter is approved comparatively.

\section{$>$ Voluntary passive euthanasia}

a person who is capable of deciding for himself decides that he would prefer to die $\&$ for this purpose he consciously will refuse to take lifesaving medicines. In this type of euthanasia, the physician will himself administer the lethal drugs voluntarily to the patient with the consent of the said. In order to terminate the pain or suffering from the terminal illness, the lethal drugs are administered to the patient by receiving an explicit consent from the patient and his family. The request of voluntary euthanasia is made only when the person is suffering from intolerable or unendurable illness and pain. There must be no chance of living for the person even if he is not subjected to those lethal substance. Then in these cases, a request for voluntary euthanasia can be made. And these requests must be made to the doctor without any coercion from the family members or any related person of the patient.

The percentage of people in favor of euthanasia are increasing but the percentage for voluntary euthanasia is not appreciable. There is a higher chance of misuse and abuse in the type of euthanasia when compared to involuntary euthanasia.

\section{Involuntary euthanasia}

is a different concept. Here, there is no request made to terminate the person from the suffering or illness. This form is to end the person's life without making a personal request. These are for example to patients who are in the permanent vegetative state, who are like vegetables, loses all the physical functioning but biologically alive. In those state, there will be no hope of recovery.

Self-autonomy and self-determination are commonly used arguments for the involuntary euthanasia.

\section{Non-voluntary passive euthanasia}

implies that the person is not in a position to decide for himself example if he is in coma or PVS.

The physician-assisted suicide is widely called as "right to die with dignity". There is no such right called right to die, but there exists the right to die with dignity.

\section{GUIDELINES:}

As mentioned earlier by the author passive euthanasia has been legalised and guidelines have been brought in but are these guidelines sufficient is to one side whereas the other side is that even passive euthanasia shouldn't be legalised as it is completely against the sanctity of life and violative of Section 299 of the Indian Penal Code, 1860.

The following guidelines were established in the Aruna Shanbaug case.

$>$ To discontinue life support, a decision has to be taken either by parents or spouse or close relatives or in the absence of any of them such a decision can be taken by a person or a body of persons who are their next friend. It can also be the doctors who were taking care of the patients.

Even if a decision is taken by the near relatives or doctors or next friend to withdraw life support, such a decision requires approval under Art. 226 from the High Court concerned. 
When such an application is filled, the Chief Justice of the High Court should forthwith constitute a Bench of at least two Judges who should decide to grant approval or not. A commission of three doctors to be nominated by the Bench, who will give a report regarding the condition of the patient. Before giving the verdict, a notice regarding the report should be given to the close relatives $\&$ the State. After hearing the parties, the High Court can give its judgment.

In Common Cause case, the following guidelines for the execution of the living will be established.

$>$ The living will should be made by an adult.

$>$ The adult must execute it in a normal state of mind \& health.

$>$ The document should indicate circumstances that treatment will only delay the process of death that may otherwise cause him or her pain, anguish, suffering \& have the executor in a state of indignity.

$>$ Unclear unambiguous living wills would not be executed.

$>$ The living will should be given by the guardian or friend, whose name has been already given in the consent form for stopping the treatment. It should be discussed with the judicial magistrate.

$>$ Execution of the will includes setting up of two medical boards \& certification by the judicial magistrate.

$>$ High Court should maintain a record of all living wills prepared within the State.

In both Aruna Shanbaug \& Common Cause case, only judicial aspects of executing euthanasia have been highlighted omitting the medical aspect.

\section{ARGUMENTS FOR LEGALISING ACTIVE EUTHANASIA BY REGULATING GUIDELINES:}

As per the guidelines are given for euthanasia in the Netherlands, the medical way of execution of euthanasia has been explained, whereas the guidelines in Aruna shanbaug only deals with the judicial aspect of executing euthanasia which is insufficient. Therefore, the cases in India where euthanasia plea was rejected are to be reconsidered.

The medical penal should be prepared \& the preparing authority must be made a quasi-judicial body. Euthanasia should be granted to the patient not only during Persistent Vegetative State but also when the patient is suffering from any other disease which is incurable in our country\& should be granted in circumstances where the treatment is so expensive that the patient could not afford for the treatment \& the State is also not offering any aid for the treatment. Passive euthanasia may not be effective in all cases therefore active euthanasia should also be legalized to ensure the right to die with dignity which is an intrinsic part of the right to life. Thus, there is a definite need in order to legalise active euthanasia in extreme cases.

Active euthanasia should be granted in the rarest of the rare case, as explained in MachhiSingh $\boldsymbol{v}$. State of Punjab $^{2}$, where the suffering of the patient is extremely high \& unbearable. In the present scheme of criminal law, it is not possible to construe the provisions so as to include voluntary active euthanasia without including non-voluntary \& involuntary active euthanasia \& many other provisions of Indian Penal Code will need drastic changes in the form of provisos \& exceptions. In Independent thought $\boldsymbol{v}$. Union of India ${ }^{3}$, it has been held that the judiciary can strike down the provisions of an Act if they are in violation of the fundamental rights. Granting of euthanasia is to be decided on a case to case basis and also a committee consisting of both medical \& legal experts have to be formed by the government in order to analyse the petitions for euthanasia $\&$ thus render a just decision. Any mala fide interest on the part of the petitioner should be effectively verified by the High Court with the help of the Committee of doctors.

There is a lack of legal framework in our country to clear the doubts about the end of life care issues in the country. Terminally ill patients who are weak \& vulnerable have to fight their own battle for the right to die with dignity. Whereas, in other cases, such as, for the rights of children \& women, backward classes, disabled people, etc., the whole society is involved to fight for their cause. In fact, the demand for justice, rightly, has resulted in various legislations protecting the rights of these groups. Considering the torment faced by the terminally ill patients, if the law provides physician-assisted suicide to them it would be a most needed step taken in the right direction. By not enacting special provisions for such patients, their right to equality is violated. Therefore, settled law \& guidelines should be brought with respect to the right to end life with human dignity.

\footnotetext{
${ }^{2}$ AIR 1983 SC 957.

${ }^{3}$ AIR 2017 SC 4904.
} 


\section{LEGAL POSITION OF EUTHANASIA IN OTHER COUNTRIES:}

Euthanasia is legal in the Netherlands, Belgium, Colombia, Luxemburg \& Canada.

The guidelines for euthanasia in Netherlands have been passed under the "Termination of Life on Request \& Assisted Suicide (Review Procedures) Act" 2002.

$>$ The physician must be convinced the patient's request is voluntary \& well-considered.

$>$ The physician must be convinced the patient is facing unremitting $\&$ unbearable suffering.

$>$ The patient is not needed to be necessarily with the terminal illness. The patient must have a correct \& clear understanding of his situation \& prognosis.

$>$ The decision should be taken with the full consent of the patient and the patient should not have alternative ideas. The patient must wish to die.

It is clearly reported that Euthanasia is legal in Netherlands, Belgium, Colombia, Luxemburg \& Canada. It is to be noted that active euthanasia is allowed in the Netherlands, Belgium, Colombia, Luxembourg and Canada. Assisted suicide is legal in Switzerland, Germany, Japan; the American states of Washington, Oregon, Colorado, Vermont, Montana California and in Washington, DC.

The execution of euthanasia should be undertaken only by the State in order to avoid violations \& infringements. Special legislations \& guidelines governing the execution of euthanasia for incompetent persons such as minors \& infants should be formulated. Therefore, it is submitted that settled law \& guidelines should be brought with respect to the right to end life with human dignity.

\section{HIPPOCRATIC OATH DEEMS EUTHANASIA} ILLEGAL:

Hypocrites must not have thought \& many, who believe that a physician or a surgeon is a healer \& a life giver, would never have thought that the oath, which he performed would be only a ritual, would be used more for professing \& less in practice. The development \& advancement in medical science is unpredictable $\&$ therefore none of the disease can be determined as incurable. Euthanasia once granted is irreversible therefore life ending decisions should not be left at stake. A disease may be incurable at the present but there are high chances of advance medicines which are successfully discovered \& administered to cure dreadful diseases. Every individual including an incompetent patient has high chances of recovery which should not be ruled out. The cherished right of life as in Art. 21 of the Constitution of India extends to receiving proper \& complete medical attention from the medical practitioner, whether working in a Government Hospital or a private practitioner.

In Mrs. Shanta v. State of Andhra Pradesh ${ }^{4}$ the court held that there appears to be some still believing that a man of medicines is a missionary \& so he takes the oath of service to the suffering human beings, in return receiving subsistence $\&$ satisfaction.

\section{SANCTITY OF LIFE:}

The protection and respect for life commence from the moment of conception as per the doctrine of the sanctity of life. And hence, according to the laws of humanity, respect for human life should be maintained from its conception. The sanctity of life is, however, about proper and full respect for human life, it, therefore requires that we respect all life and never intend its destruction or ending that all human life has equal value, regardless of its stage of development or its quality.

Therefore, it is contented that there is no need for consideration of settled law and guidelines with respect to Right to end life with human dignity.

\section{OBLIGATORY PROTECTORS:}

One of the major disadvantages of legalizing assisted suicide and euthanasia is the misuse of this statute. There is a greater chance of potential abuse of physician-assisted suicide or euthanasia when it is legalized in real. Thus, to prevent these abuses, the system must be made clear before the law is made. For example, a psychiatrist may be appointed to analyze the mental condition and eligibility of the person before the physician-assisted suicide or euthanasia is done. Certain guidelines have to be framed before the administration of the lethal drugs.

\section{There must be voluntary written consent:}

Before euthanasia, the consent has to be obtained from the victim. The consent must be persistent, voluntary, informed and the person must be competent during that time. The written consent is

\footnotetext{
${ }^{4}$ AIR 1998 AP 51.
} 
essential because we can prevent the misuse and abuse. Even though these safe guards are implemented out of 5 euthanasia deaths, 1 is done without the consent of the victim. The judicial system has also failed to bring these cases into consideration due to lack of evidence. According to the reports submitted, in the Netherlands, in the year 2005, out of 2410 deaths due to euthanasia and PAS, more than 560 deaths were done by the doctors without getting the explicit consent from the victim. Even in Belgium, 66 deaths out of 208 were done without getting consent. The percentage in Belgium is three times higher than the reports taken from the Netherlands.

\section{Reports by physicians are mandatory:}

Every euthanasia and PAS deaths must be reported to the respective committees and federal jurisdictions. But $40 \%$ of these deaths go unnoticed and are not reported. Many such cases go unreported because the traces of those are not even found.

\section{By physicians:}

The lethal drugs used must be administered by the physicians only. But in most of the cases, the nurses are allowed to do the agency of the drugs. According to a report, almost $12 \%$ of the euthanasia deaths are administered by nurses and in which $45 \%$ are done without explicit consent.

\section{Double consultation:}

The decision before finalizing must be checked again by another doctor. And that doctor must be independent. He must not have any relationship with the patient or their family. The people who must not be administered by PAS or euthanasia are affected because of misconception.

Even though there are these measures to prevent and protect the unwanted death of patients, the percentage of those deaths are still high. As many cases go unreported, a proper measure to solve this issue is not found.

\section{MERCY KILLING AND EUTHANASIA:}

The maximum of the people thinks that mercy killing and euthanasia are same. But there are differences between the both. The output of both the practice is death but the reason and the objectives differ. Mercy killing is done because of sympathy for many reasons and euthanasia is done to conclude the pain and suffering who have no hope of recovery.

The reasons for mercy killing may be insanity or incurable malady. It will be reported by the members of the family. The person who dies in mercy killing needs to be a patient. The person may suffer from serious physical or mental illness. The main motivation for mercy killing is the lack of duty to care.

Euthanasia and mercy killing differ in various features. The risk of misuse and abuse is greater in mercy killing than euthanasia. Unlike euthanasia, mercy killing do not require explicit consent from the patient. In euthanasia, the victim must be patient who is under the care of a doctor which is not necessary for the mercy killing.

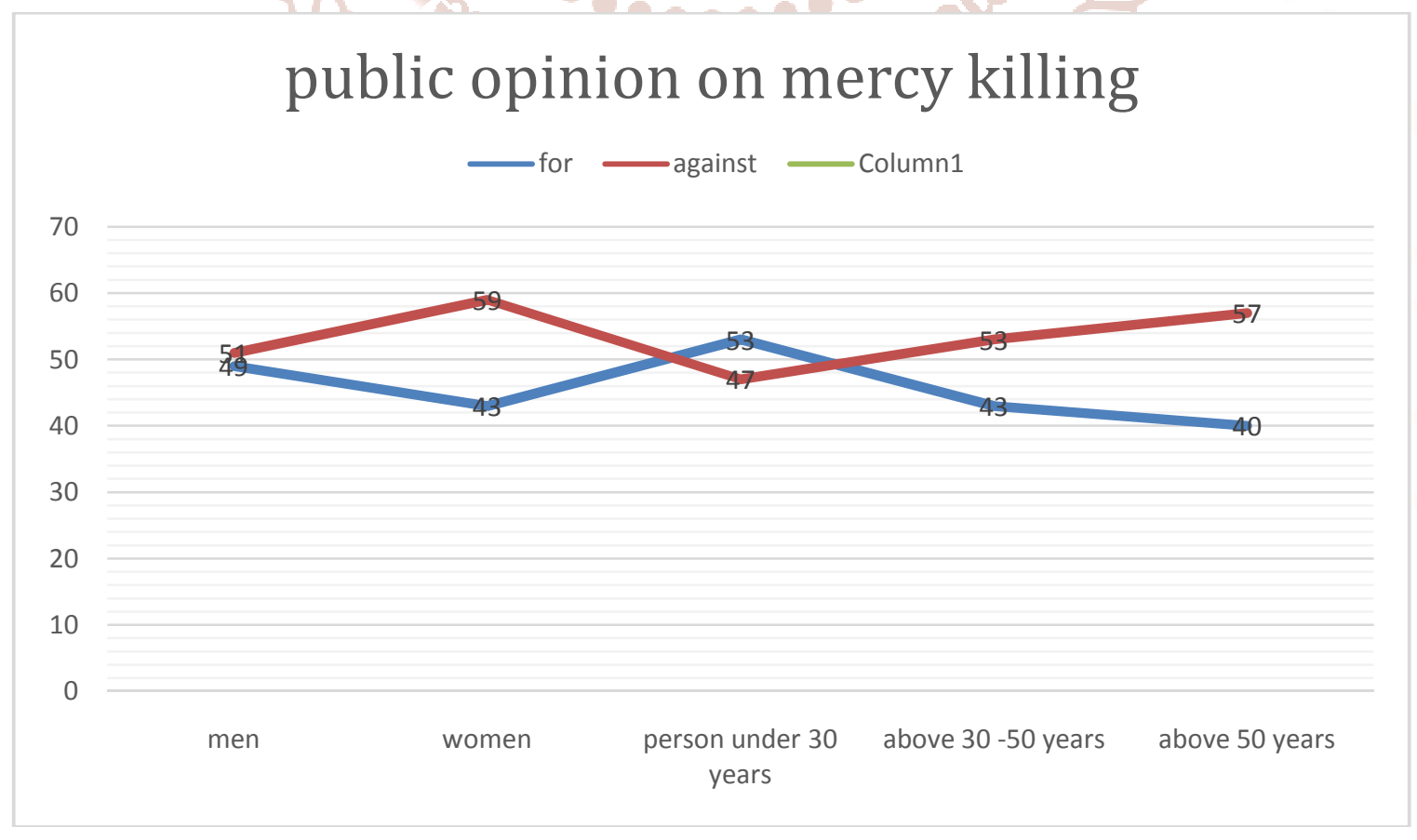


The above graph explains the view of the general public on mercy killing. People of the different age group have different opinion on mercy killing. Form the reported cases on mercy killing, various decisions and judgements were given to the convicted persons.

Euthanasia and mercy killing should not be confused. In euthanasia, the patient has not only sympathy but self-determination and self-autonomy. The consent of the patient is explicitly received. The regulation by state and medical assistance is mandatory which lacks in the mercy killing.

Even though the base of both mercy killing and euthanasia are sympathy and suffering, it can no way be equated. Euthanasia is sternly for the patients who are suffering terminal illness and there is no chance of recovery. But mercy killing is for differently abled who has every right to live a dignified life. It is inferred that judiciary should play a distinctive role.

\section{PHYSICIAN-ASSISTED SUICIDE:}

The term assisted suicide refers to the suicide in the assistance of another person, mostly a physician. This is called Physician-assisted suicide. The patient will be given a lethal drug dose in case of suffering from serious illness and severe pain. This will most likely happen only under the doctor's prescription. And a lawyer may also be involved in the case of clarification.

Speaking of voluntary active euthanasia, it is the involvement of the physician by administering the lethal dose into the patient's body by the means of injection or so. But, physician-assisted suicide is the patient, and not the physician who is administering the drug. The patient himself will subject him with a drug. The passive euthanasia is to kill someone by not providing the food, or by stopping the necessary elements that are required by the patient for the survival.

The difference between the voluntary active euthanasia and physician-assisted suicide the person who administers the lethal drug. According to the Penal Code 1860, euthanasia is an offence under section 302 (punishment for murder) or under section 304 (culpable homicide not amounting to murder). Suicide is also considered as an offence under section 309 (attempt to commit suicide) of the Indian Penal Code. The right to suicide is not an available right is India and it is considered illegal.

\section{Drugs used in PAS:}
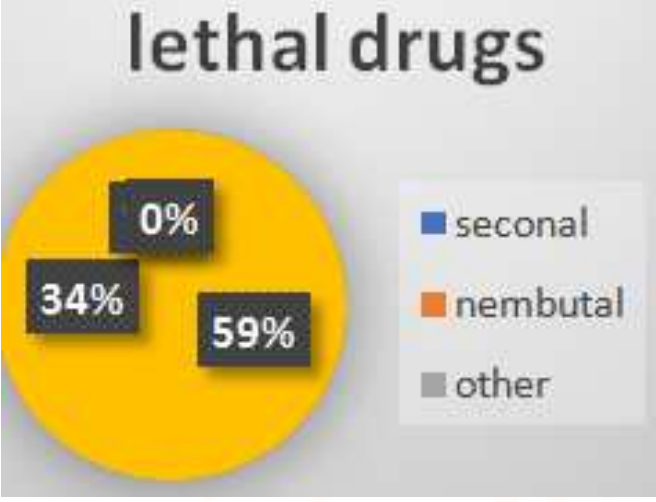

Under the death of dignity Act, the drugs used for PAS are,

Secobarbital (Seconal) $\quad 59.3 \%$

Pentobarbital (Nembutal) $\quad 34.3 \%$

Other

$6.5 \%$

the secobarbital and pentobarbital are sedative drugs. The pentobarbital is stopped from the usage because of the protest happened due to the usage of it in the capital punishments. Thus, seconal has been widely used for death. The doctor prescribed usage of seconal is, $9000 \mathrm{mg}$. to in capsule form.

Until now none of the doctors has precisely prescribed any drugs for suicide. But, due to the high cost of a seconal drug other drugs have been tested as an alternative. And some of them burned the mouths of the patient and wasn't successful.

\section{ADMINISTRATION:}

Oral intake is not the only means of administration of the lethal dose. Many cases of physician-assisted suicide have reported the death using syringe and IV infusion.

The consumption of seconal is $9 \mathrm{~g}$. in the form of a capsule and pentobarbital is $10 \mathrm{~g}$. in the form of liquid.

\section{SUICIDE:}

Suicide, or ending one's own life, is a catastrophic event with strong emotional consequences for its survivors and for families of its victims. But it has been a common phenomenon in today's world. In Naresh MarotraoSakhre v. Union of India, the Bombay High Court also observed that suicide by its very nature is an act of self-killing or self-destruction, an act of terminating one's own act and without the help of any other human agency.

\footnotetext{
${ }^{5}$ Naresh MarotraoSakhre v. Union of India (1996) 1 BomCR 92.
} 
Every year nearly 800000 people kill themselves and there are many more people who try to commit suicide. Every suicide is a disaster that affects families, societies and the entire nation. It hasa longlasting effect on the people left behind. Suicide occurs all over the lifetime and was the second foremost cause of death among 15-29-year-olds globally in 2016. Suicide does not just occur in high-income societies but is also a global spectacle in all regions of the world. In fact, over $79 \%$ of global suicides occurred in low- and middle-income societies in 2016. Suicide is a grave people's health problem. However, suicides are able to be prevented with timely, evidence-based and often low-cost interventions. For national responses to be operative, a comprehensive multisectoral suicide prevention strategy is required.

Every year, almost $1,00,000$ people dies by committing suicide in India. The number of people die by committing suicide in the country during the decade (2005-2015) have logged an increase of $17.3 \%$. The increase in the number of suicides was informed each year till 2011 thereafter a declining trend has been noticed until 2014 and it again increased by $1.5 \%$ in 2015 over 2014.

NUMBER OF DEATH DUE TO SUICIDES AND RATE OF SUICIDES IN INDIA 2011 TO 2015:

\begin{tabular}{|l|l|l|l|}
\hline SI. N & Year & Number of Suicides & Rate of Suicide \\
\hline
\end{tabular}

\begin{tabular}{|c|c|c|c|}
\hline 1 & 2011 & $1,35,585$ & 11.2 \\
\hline 2 & 2012 & $1,35,445$ & 11.2 \\
\hline 3 & 2013 & $1,34,799$ & 11.0 \\
\hline 4 & 2014 & $1,31,666$ & 10.6 \\
\hline 5 & 2015 & $1,33,623$ & 10.6 \\
\hline
\end{tabular}

\section{SUICIDE AS A CRIME IN INDIA:}

The Constitution of India under part-3 has guaranteed right to life as a fundamental right. Prima facie this fundamental right is given not to deprive any person of his life. Every individual has his/her right to lead quality, meaningful and a dignified life wherein he is not deprived from his personal liberty. Article 21 of the Indian Constitution states that - 'no person shall be deprived from his life or personal liberty except according to procedure established by law'. But this right does not include the right to die.

The question of whether the right to die is an intrinsic part of Art. 21, was first raised in the case of State of Maharashtra v. MaruthiSripatiDubal ${ }^{6}$, wherein
Right to die was recognized as a part of Art. 21 \& attempt to commit suicide was declared to be unconstitutional. In P. Rathinam v. Union of India ${ }^{7}$, the divisional bench affirmed the view of M.S. Dubal. Later in Aruna Shanbaug v. Union of India ${ }^{8}$, passive euthanasia was legally recognized \& guidelines for its execution were established. In Common Cause $v$. Union of India', guidelines, for the execution of the living will was established \& right to die with dignity was recognized as a part of Art. 21.

This issue again raised in the court in the case ofGian Kaur v. State of Punjab ${ }^{10}$.In this reported case a five judge Constitutional Bench of the Supreme Court of India overruled the P. Ratinam's case $\boldsymbol{e}^{11}$ and held that "Right to Life" under Article 21 does not include "Right to die" or "Right to be killed" and there is no such ground to hold that the section 309, IPC is constitutionally unenforceable. To theactual meaning of the word, 'life' in Article 21 means life with human dignity. Any aspect of life which makes life dignified may be included in it but not that which quenches it. The 'Right to Die' if any, is integrally unpredictable with the "Right to Life" as is "death" with "Life".

Under $\$ 309$ of The Indian Penal Code of 1860 states that attempt to commit suicide is- Whoever attempts to commit suicide and does any act towards the commission of such offence, shall be punished with imprisonment for a period which may extend to one year [ with fine, or with both]. Death or termination of a person's life in an unnatural way by one's own self is immoral as well as legally punishable.

Also aiding a person to end his life who is willing to commit suicide is punishable under law. In India, under sections 305 and 306 of the I.P.C., 1860, abetment of suicide is explicitly punishable. In the case of Sanju v. State of Madhya Pradesh ${ }^{12}$, the honourable Supreme court defined 'abet' as meaning to aid, to assist or to give aid, to command, to procure, or to counsel, to countenance, to encourage, or to use someone to commit. The definition of 'abet' as laid down, makes it clear that abetment only occurs when there are at least two persons involved, which further directs us towards the arrangement and operation of

\footnotetext{
7 (1994) SCC 394.

81994 SCC (3) 394.

${ }^{9}$ (2011) 4 SCC 454.

${ }^{10}$ (1996) SCC 648.

${ }^{11} \mathrm{P}$ Rathinam v. Union of India (1994) SCC 394.

${ }^{12}$ (2002) 5 SCC 371
} 
the act. Abetment of suicide of child or insane person is if any person under eighteen years of age, any insane person, any delirious person, any idiot, or any person in a state of alcoholism, commits suicide, whoever abets the commission of such a crime, shall be punished with death or imprisonment for life, or imprisonment for a term not more than ten years, and can also be legally responsible to fine. ${ }^{13}$

Also, abetment of suicide is when any person commits suicide, whoever abets the commission of such suicide, shall be punished with imprisonment of either description for a term which may extend up to ten years of the time period, and shall also be accountable to fine. ${ }^{14}$ If a person intentionally aids or helps in committing of offence or omitting an act in order for the offence to take place is said to abet a crime. Mere intention to aid or render help cannot be termed as abetment.

A person is guilty of abetment when he induces someone to commit an offence like suicide (or) he is part of a plan to make a person commit suicide (or) he is intentionally helping the victim to commit suicide by doing or not doing something that he was supposed to do.

The clear mens rea to commit the offence is a sine qua non for persuasion under Section 306 IPC-

$>$ Not only because a wife has committed suicide in matrimonial house, husband and in-laws can't be charged for abetment to suicide.

$>$ Clear mens rea has to present in order to charge a person under abetment

With the criminalising of the act of merely aiding or abetting a person to commit a suicide we can clearly infer that Right to life is an inalienable and inherent right of every human being. A similar act to abetment to suicide is euthanasia. Euthanasia refers to the practice of ending a life in a manner which relieves pain and suffering or in other words it is a deliberate intervention undertaken with the explicit intention to end a person's life, to relieve intractable suffering.

\section{CONCLUSION:}

From all the above-discussed topics and types, we could infer about the restrictions, guidelines, enactments of euthanasia, PAS, and suicide. These forms are not accepted in many parts of the world.

\footnotetext{
${ }^{13} \S 305$ of I.P.C 1860

${ }^{14} \$ 306$ of I.P.C 1860
}

Controversies and debates are taking place in various states about legalising each of them. Judgements and decisions also alter. Moral values also differ from person to person in this delicate topic. Thus, the author concludes by giving only the idea of each forms and do not determine any of the functions.

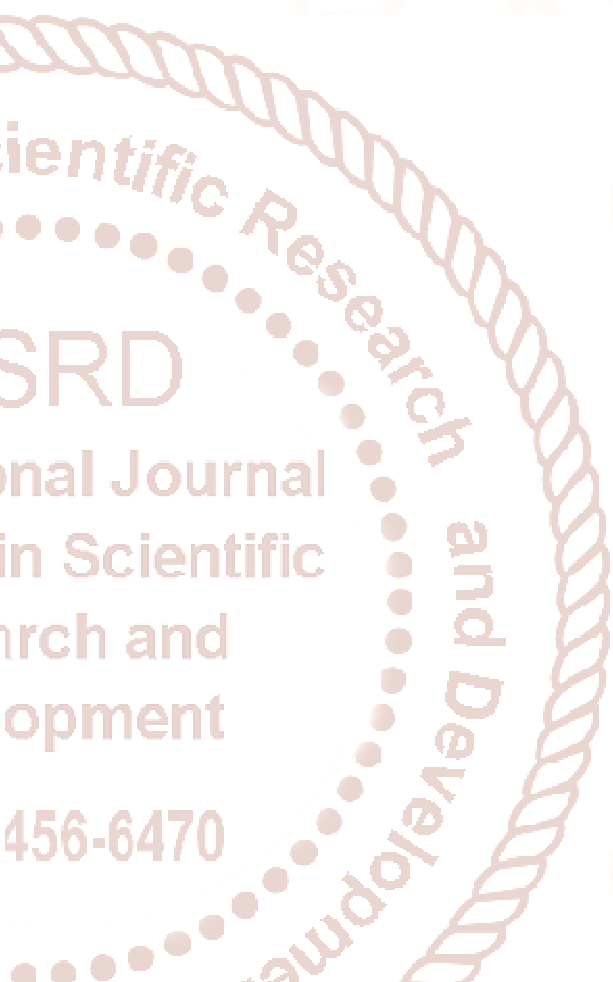

